\title{
NOTAS SOBRE COMBATES: CAPITALISMO, FLUXOS ESQUIZOS E SUBJETIVIDADES
}

Fábio Batista ${ }^{1}$

\begin{abstract}
Resumo: Trata-se aqui de apresentar, a partir de Deleuze, Guattari e Foucault, uma leitura do imbricamento entre capitalismo, fluxos esquizos e subjetividades. As questões orientadoras são: de que modo capitalismo e fluxos esquizos se opõem? A partir dos fluxos esquizos emergem novas/outras subjetividades, subjetividades individuais/coletivas combativas? A hipótese que apresentarei é de que embora o capitalismo se reinvente e avance, existem modos de vida combativos que põe em xeque o próprio capitalismo. Ou seja, a exploração e dominação capitalistas encontram seu contraposto em modos de vida que inventam outros espaços-tempos, outros modos de fazer e ver: outras subjetividades. Assim apresentar-se-á: a) Antonin Artaud e Vincent Van Gogh. b) no cinema, uma breve leitura do filme "Clube da luta". Por fim, c) no teatro a Cia Ueinzz. Na medida em que pintura, literatura, cinema, teatro podem ser espaços de criação e criação de subjetividades combativas.
\end{abstract}

Palavras-chave: Capitalismo; fluxos esquizos; desejo; subjetividades.

\begin{abstract}
Our purpose here is to present, from Deleuze, Guattari and Foucault, a reading of the the imbrication of capitalism, schizzes-flows and subjectivities. The guiding questions are: how capitalism and schizzes-flows can oppose? Beginning in the schizzes-flows emerge new/others subjectivities - individual/collective subjectivities combative? The hypothesis that I will present is that although the capitalism reinvent itself and advance, there are combative ways of life that put in check the capitalism itself. Namely, the capitalist exploitation and domination finds its counterpoint in ways of life that invent other spaces-times, other ways to do and see: other subjectivities. So I will clarify: a) Antonin Artaud and Vicent Van Gogh. b) in the movies, a brief reading of the film "Fight Club". Finally, in the theater with the Cia Ueinzz. While the painting, the literature, the movies can be spaces of creation and creation of subjectivities combative.
\end{abstract}

Keywords: Capitalism, schizzes-flows, desire, subjectivities.

\section{Introdução}

Disse um jovem francês: "Viver, não é sobreviver" (DELEUZE, 2006, p. 319)'. Eis uma máxima, um princípio prático para todo e qualquer tempo e espaço, digna de ser vivida por todos nós. Pois certamente viver está além do simples sobreviver: um "doente" sobrevive, mas aquele que abraça a vida vive. Nosso objetivo é apresentar breves reflexões (notas) sobre modos de vida afirmativos no contexto do capitalismo e dos diversos dispositivos de podersaber, modos de vida que implicam em produção de subjetividades individuais/coletivas que põem a máquina capitalista em xeque: i) arte: um campo de experimentação de subjetividades artísticas; ii) "Clube da luta”: produção de subjetividades anárquicas?; iii) Ueinzz: um teatro

\footnotetext{
${ }^{1}$ Doutorando em filosofia pela Universidade Estadual do Oeste do Paraná - UNIOESTE/Toledo. Contato: fabiobatista1985@bol.com.br
} 
esquizo/processos de dessubjetivação? Vejamos inicialmente como Deleuze e Guattari pensaram este tema.

De acordo com os dois filósofos franceses, a máquina capitalista civilizada operara o seu funcionamento a partir de fluxos descodificados e desterritorializados. ${ }^{\text {ii }}$ (Ou seja, a partir daquilo que constituía o pânico das outras formações sociais, portanto ela é o limite de todas as outras sociedades. Pois enquanto a máquina territorial selvagem codificava os fluxos e a máquina imperial despótica sobrecodificava os fluxos, ela, a capitalista funciona a partir de fluxos descodificados, mas axiomatizando-os: o que ela descodifica com uma mão, axiomatiza com a outra). O que, para Deleuze e Guattari, implica em afinidade com o processo, a viagem esquizofrênica. Como? Para Deleuze e Guattari o processo esquizofrênico é a passagem dos fluxos descodificados do desejo: o esquizo é aquele que emite e faz passar os fluxos descodificados, que descodifica todos os fluxos. Portanto, em ambos os casos: fluxos descodificados, desterritorializados. Mas, como veremos, se há uma afinidade ao nível dos fluxos descodificados há, por outro lado, uma hostilidade ao nível do uso e "objetivo" desses fluxos.

Deleuze e Guattari (Cf. 2010) tomam: 1. a esquizofrenia ${ }^{\text {iii }}$ como a realidade mesma do desejo; 2. a esquizofrenia é o limite sempre conjurado do capitalismo 1 . Trata-se de pensar o desejo não mais a partir da perspectiva psicanalítica - o desejo como falta -, mas pensa-lo como aquilo que produz. É aí que a esquizofrenia entra em substituição ao neurótico psicanalítico: aquilo que os autores chamam de viagem esquizofrênica, e não, certamente a entidade clínica, ou o esquizo de hospital. Diz Mengue (2008, p. 274): “Com a esquizofrenia, o inconsciente aparece, finalmente, em sua desnudez, em sua realidade verdadeira". 2. Contudo a máquina capitalista sempre regula (ao menos procura regular) os seus fluxos descodificados não os deixando passar livremente, antes fazendo os funcionar a seu favor: produção de mais capital. De modo que o esquizo (compreendido aqui como aquele que emite fluxos descodificados de desejo) nem sempre é deixado em seu canto; é, por vezes, cooptado, isto é, os fluxos de desejos são bloqueados/coagulados ou direcionados ao objetivo da máquina capitalista - ou o esquizo é transformado em uma entidade de hospital (procedimento que parece mais comum) ou transformado em produtor de algo a ser consumido. Isto porque os fluxos esquizos são o limite do capitalismo. Diz Deleuze, e aqui retomamos o ponto de afinidade e hostilidade entre capitalismo e esquizofrenia: 
trabalho, etc, introduz um novo tipo de máquina. Ao mesmo tempo - não depois constitui uma máquina que já não é de codificação: uma máquina axiomática. Assim é como virá a ser um sistema coerente. O esquizo, em troca, sempre dá mais. Já não se deixa axiomatizar, vai sempre mais longe com os fluxos descodificados (DELEUZE, 2005, p. 24).

O capitalismo, portanto, funciona a partir dos fluxos descodificados e desterritorilizados, mas sempre procura mantê-los nos limites internos que ele sempre alarga. A esquizofrenia, por sua vez, também opera a partir dos fluxos descodificados e desterritorilizados, mas procura sempre ir mais longe, para além dos limites internos impostos pela máquina capitalista. É por isso que ela é o limite absoluto do capitalismo, aquilo que o põe em xeque.

\section{Arte: um campo de experimentação de subjetividades artísticas}

Desse modo no socius civilizado ${ }^{\mathrm{iv}}$ encontramos o combate entre máquina capitalista e esquizofrenia. De tal modo que a esquizofrenia (compreendida como fluxo esquizo) é aquilo que realiza, ou pode realizar a ultrapassagem, como diz Deleuze: derrubar o muro. Tal como o fizeram Artaud e Van Gogh, respectivamente, com suas máquinas literário-teatrais e pictóricas, minando e solando a máquina capitalista civilizada. Artaud, por exemplo, em sua peça radiofônica: "Para acabar com o julgamento de Deus" (1948), começa com o uso muito particular da língua: elimina toda coerência sintática e semântica e a põe a funcionar sob outro modo, um modo pouco habitual e muito particular ao seu universo. Ele também foi aquele que primeiramente falou em "pensamento sem imagem" e "corpo sem órgãos". Em ambos os casos vale notar o "sem": "pensamento sem imagem" e "corpo sem órgãos", ou seja, Artaud buscava se desvencilhar daquilo que determina de saída o pensamento e o corpo. Artaud, assim, procurava um tipo de pensamento que não estivesse atrelado às categorias tradicionais que definiam o pensamento: lógica; representação. Já o "corpo sem órgãos" é uma batalha empreendida por Artaud mais precisamente contra a organização dos órgãos. Muito provavelmente porque ele esteve em uma instituição psiquiátrica que lhe impunha a organização e a funcionalidade de cada órgão. Não se trata de um desprezo do corpo, mas o modo como se investe socialmente os órgãos na máquina capitalista. Em especial os órgãos daquele que é considerado "doente mental", o que foi o caso dele. Sobre Van Gogh e o processo esquizofrênico temos uma importante passagem de uma entrevista com Deleuze e Guattari (2006, p. 303-304) que, embora seja um pouco extensa, vale ser citada: 
Questão: Nietzsche, Van Gogh, Roussel, Campana: o que significa nesses casos a doença mental?

Gilles Deleuze. - Ela significa muitas coisas. Jaspers e, hoje, Laing disseram coisas muito fortes sobre isso, mesmo se até agora eles não foram muito bem compreendidos. Eles disseram, em resumo, que naquilo que é chamado, grosso modo, loucura, há duas coisas: há um furo, um rasgo, como uma luz repentina, um muro que é atravessado; e há, em seguida, uma dimensão muito diferente, que poderíamos chamar um desabamento. Um furo um desabamento. Lembro-me de uma certa carta de Van Gogh. 'Devemos - escrevia ele - minar o muro'. Salvo que romper o muro é dificílimo e se o fazemos de forma muito bruta nos machucamos, caímos, desabamos. Van Gogh acrescentava ainda que 'devemos atravessá-lo com uma lima, lentamente e com paciência'. Temos então o furo e depois esse desabamento possível. Jaspers, quando fala do processo esquizofrênico, ressalta a coexistência de dois elementos: uma espécie de intrusão, a chegada de algo que não tem nem mesmo expressão, algo de formidável e que o é, a tal ponto que é difícil dizê-lo, tão reprimido em nossas sociedades que corre o risco de coincidir - e eis o segundo elemento - com o desabamento. Reencontramos aí o esquizofrênico autista, aquele que não se mexe mais, que pode permanecer imóvel durante anos. No caso de Nietzsche, de Van Gogh, de Artaud, de Roussel, de Campana, etc., há sem dúvida coexistência desses dois elementos: um furo fantástico, um buraco no muro. Van Gogh, Nerval - e quantos outros poderíamos citar! - quebraram o muro do significante, o muro do Papai-Mamãe, eles estão bem além, e nos falam com uma voz que é aquela de nosso futuro. Mas o segundo elemento permanece de qualquer modo presente nesse processo, e é o perigo do desabamento. Que o furo, o rasgo possam coincidir ou deslizar numa espécie de desabamento é algo que ninguém tem o direito de tratar de forma leviana. É preciso considerar esse perigo como fundamental. As coisas estão ligadas. [...].

A passagem acima mostra o que os dois filósofos franceses compreendem por processo esquizofrênico a partir de Jaspers e Laing (o primeiro filósofo e o segundo psiquiatra): o furo e o possível desabamento. E mais: nossa sociedade reprime sem parar esta viagem, ou seja, reprime sem parar aqueles que se lançam em direção aquilo que nos põe para além dos limites internos da máquina capitalista. E é por isso que o capitalismo trata de axiomatizar os fluxos esquizos (o processo esquizofrênico) porque vê neles sua própria morte vinda de dentro. Quando virá aquela, que de fora, porá termo a sua potência de sempreexpansão interna e regulação?

\section{“Clube da luta": produção de subjetividades anárquicas?}

Pode-se também, para além dos exemplos já mencionados, para exemplificar o caráter produtivo do desejo (e de produção de subjetividades libertárias) pensado a partir do processo esquizofrênico, recorrer ao cinema: o filme, "Clube da luta"v.

Clube da Luta é um clássico. Cheios de referências e fãs fiéis. A história é a seguinte: uma pessoa (Edward Norton), que em alguns lugares é intitulada 'narrador' (esta mania de dar nome a tudo...), é reprimida pela sua vida. Tem um emprego que paga bem, possui roupas caras... porém, tem insônia. 
Sua insônia acaba quando ele começa a frequentar grupos de ajuda (câncer de testículos, tuberculosos, pneumonia, etc.). Sua calmaria termina quando uma mulher, também impostora, passa a visitar os mesmos grupos. Marla Singer (Helena Bonham Carter - O Discurso do Rei e Franquia Harry Potter,) passa a perturbar a mente da pessoa (Norton, [...]). Neste meio tempo, o narrador conhece o misterioso Tyler Durden (Brad Pitt) e assim se tornam GRANDES amigos. E de tão amigos que se tornam, acabam criando um clube, o clube da luta, cheio de regras para serem seguidas ("A primeira regra do Clube da Luta é: não comente sobre o Clube da Luta') (BIA, 2012).

Mas, vale dizer um pouco mais: o filme mostra o modo como o personagem de Edward Norton entra em um processo de produção esquizo, tornando-se uma espécie de militante anárquico que faz uma guerrilha urbana sobre todo o campo social dos E.U.A. Com Tyler Durden, que é seu outro e, no entanto, é ele mesmo, (pode-se dizer que Tyler Durden é a própria produção do inconsciente do personagem de Edward Norton) não só criam o clube da luta onde a eles vem somar muitos homens; mas juntos, o narrador/Tyler Durden arquitetam o projeto de desmontar o capitalismo: juntos visavam quebrar o sistema de cartões de crédito e causar o caos zerando todas as dívidas existentes. Como? Implodindo os prédios que armazenavam os dados dos cartões de crédito. Assim, entre todos os fios do filme, nos importa destacar: 1. o processo esquizo, ou seja, o caráter produtivo do desejo do personagem de Edward Norton; 2. esta produtividade põe em xeque aquilo que o axiomatiza: a máquina capitalista. Trata-se, talvez, daquilo que Deleuze (Cf. 2005) chama de investimento revolucionário do campo social (embora o filme tenha um caráter, por vezes, niilista: ou seja, um forte foco na destruição; ou por vezes reacionário: um culto a personalidade do personagem de Edward Norton pelos demais componentes do clube; o que implica, acima de tudo, na possibilidade de uma organização hierarquizada e cega). Vale ainda recorrer a um experimento cênico, ao laboratório teatral da Cia Ueinzz para pensar o combate em outro território, mas atrelado aos dois primeiros. Combate contra o capitalismo, em especial contra o biopoder o qual permite o seu funcionamento e operacionalidade.

\section{Ueinzz: um teatro esquizo/processos de dessubjetivação?}

A Cia Teatral Ueinzz nasce em 1997 no interior de um hospital psiquiátrico (HospitalDia A Casa SP), no campo institucional disciplinar, no campo da vida que se administra. Mas se afasta daí e vai se inventar em outro espaço para além dos muros e paredes institucionais, para além dos dispositivos de poder-saber do biopoder. Em uma espécie de contra-ataque em que a vida volta-se sobre o domínio sobre a vida e afirma-se novamente criando novas vias de expressão, imaginação, sentimentos, entendimentos e sensibilidades. 
O professor, terapeuta e filósofo Peter Pál Pelbart é uns dos coordenadores da Companhia e permanece nela até hoje. Mas a Companhia não é obra de um homem só: "A sugestão de fazer uma peça com pacientes surgiu ao mesmo tempo de um dos usuários, Alexandre, e dos terapeutas, que desenvolvem diferentes atividades na Casa, um hospital de regime aberto. Dois diretores teatrais bancaram a ideia: Sergio Penna, que já havia trabalhado com pacientes mentais de Santos e São Vicente, e Renato Cohen, diretor do grupo Orlando Furioso e professor de semiótica da PUC" (DÁVILA, 2001).

Desde 2009 o espaço cultural "O barco" abriga a Cia Ueinzz. E do início até hoje já fizeram muitas apresentações não só no Brasil como em outros países: Alemanha e Escócia, por exemplo. Mas deixemos de lado a propaganda e passemos ao estranho nome da companhia: é Pelbart quem nos diz que:

\begin{abstract}
Num dos ensaios subsequentes, os diretores coordenam um exercício teatral sobre os diferentes modos de comunicação entre seres vivos: palavras, gestos, postura corporal, som, música, tudo serve para comunicar-se. Um exercício clássico sobre as várias linguagens de que se dispõe: cada animal tem a sua língua, cada povo tem a sua, às vezes cada homem tem seu próprio idioma, e não obstante nos entendemos, às vezes. Pergunta-se a cada pessoa do grupo que outras línguas fala, e o paciente do gemido, que nunca fala nada, responde imediatamente e com grande clareza e segurança, de todos incomuns nele: alemão. Surpresa geral, ninguém sabia que ele falava alemão. Foi preciso o ouvido de dois estrangeiros para escutarmos que aquele que acompanhamos há muito tempo falava "alemão". E que palavra você sabe em alemão? Ueinnz... E o que significa Ueinzz em alemão? Ueinzz. Todos riem - eis a língua que significa a si mesma, que se enrola sobre si, língua esotérica, misteriosa, glossolálica (PELBART, 2000a, p. 99).
\end{abstract}

De tal acontecimento nasceu o nome da companhia: Ueinzz.

Nossa hipótese é de que esta companhia não só funciona como um tipo de terapêutica, mas também espaço de criação e criação de subjetividades outras, em última instância: espaço de dessubjetivação. Se o capitalismo, como pensa Guattari (Cf. 1996), produz e precisa produzir subjetividades. Foucault (1995, p. 239) afirma: "É preciso promover novas formas de subjetividade, recusando o tipo de individualidade que nos foi imposto por tantos séculos". A companhia mistura e desarranja o já dado e formado e conduz os usuários do serviço de saúde mental e todos os demais componentes a novas formas de sentir, pensar, agir e perceber. Não se trata mais da divisão normal e anormal, doente mental e homem saudável, mas de encontros e ressonâncias entre corpos e sentidos, olhares e respirações, palavras e gestos.

Em uma provável proximidade com a língua de Artaud encontra-se no site "Núcleo de Estudos da Subjetividade" - pós-graduação em psicologia clínica da puc-sp - uma espécie de verbete/apresentação da Cia: 
Ueinzz é território cênico para quem sente vacilar o mundo. Como em Kafka, faz do enjoo em terra firme matéria de transmutação poética e política. No conjunto, há mestres na arte da vidência, com notório saber em improviso e neologismos; especialistas em enciclopédias marítimas, trapezistas frustradas, caçadores de sonhos, atrizes interpretativas. Há também inventores da pomba-gíria, incógnitas musicais, mestres cervejistas e seres nascentes. Vidas por um triz se experimentando em práticas estéticas e colaborações transatlânticas. Comunidade dos sem comunidade, para uma comunidade por vir ${ }^{\mathrm{vi}}$ ".

Portanto não se trata, neste teatro, de representação e representação da vida tal como dada. Trata-se, sobretudo de criar um campo de emergência de outros modos de vida. Embora, certamente, não servindo de modelo serve como campo de experimentação a todos que dele participam. Pois "nesse teatro cada subjetividade pode continuar tecendo-se a si mesma, com a matéria-prima precária que lhe pertence, e retrabalha-la. Subjetividades em obra em meio a uma obra coletiva, no teatro concebido como um canteiro de obras a céu aberto" (PELBART, 2000, p. 105).

\section{Considerações finais}

Como o título indica trata-se de notas sobre tema(s) que atravessam e cruzam os pensamentos de Deleuze, Guattari e Foucault. Nosso intento foi trazer e somar tais perspectivas e criar um texto-caleidoscópico sobre os possíveis modos de combate frente à máquina capitalista. Dos dois primeiros apresentamos suas concepções sobre o capitalismo e os fluxos esquizos (isto é, a teoria do desejo formulada por ambos em $O$ Anti-Édipo). E de Foucault e Guattari a noção de subjetividade e dessubjetivação.

Assim o texto aqui se encerra, mas os combates são permanentes. Todos os combates contra toda forma de dominação, exploração e sujeição são válidos: seja estético-político; político-social. Tudo está amarrado. Seja no front com Artaud e Van Gogh; sejam com Tyler Durden, ou ainda, com a Cia Ueinzz os combates são imprescindíveis para a produção de novos modos de vida, novas formas de subjetividades para além do capitalismo que hoje ainda impera. Portanto, para os filósofos franceses (Deleuze, Guattari e Foucault) trata-se de saber como unir todas as máquinas que podem investir revolucionariamente o campo social. Eis a rica tarefa na qual eles se lançaram, e eis a tarefa que podemos retomar na medida em que podemos nos situar como herdeiros deles e lavá-la adiante.

\section{Referências:}

ARTAUD, A. Escritos de um louco. Disponível em: [http://www.sabotagem.cjb.net/]. [25/05/2016]. 
BIA. 2012. Clube da luta. Disponível em: [http://www.cinemadebuteco.com.br/criticas/acao/clube-da-luta-2]. [25/05/2016].

DÁVILA, M. 2001. Ueinzz comemora cinco anos com "Gothan SP". Disponível em: [http://www1.folha.uol.com.br/fsp/ilustrad/fq2410200122.htm]. [25/05/2016].

DELEUZE, G.; GUATTARI, F. 2010. O anti-Édipo: capitalismo e esquizofrenia. São Paulo: Ed. 34.

2006. Pensamento nômade. In:

A ilha deserta e outros textos: textos e entrevistas (1953-1974). São Paulo: Iluminuras.

. 2006a. Capitalismo e esquizofrenia. In:

A ilha deserta e outros textos:

textos e entrevistas (1953-1974). São Paulo: Iluminuras.

DELEUZE, Gilles. 2005. Derrames: entre el capitalismo y la esquizofrenia. Buenos Aires: Cactus.

FOUCAULT, M. 1995. O sujeito e o poder. In: RABINOW, P.; DREYFUS, H. Michel Foucault uma trajetória filosófica: para além do estruturalismo e da hermenêutica. Rio de Janeiro: Forense Universitária.

GUATTARI, F.; ROLNIK, S. 1996. Micropolítica: cartografias do desejo. $4^{\text {a }}$ edição. Petrópolis: Vozes.

MENGUE, Philippe. 2008. Deleuze o el sistema de lo múltiple. Buenos Aires: Las Cuarenta.

PELBART, P. P. 2000. Eu (reka!). In: A vertigem por um fio: políticas da subjetividade contemporânea. São Paulo: Iluminuras.

. 2000a. Ueinzz - Viagem a Babel. In: A vertigem por um fio: políticas da subjetividade contemporânea. São Paulo: Iluminuras.

. 2000b. Subjetividade esquizo. In: A vertigem por um fio: políticas da subjetividade contemporânea. São Paulo: Iluminuras.

\footnotetext{
' Deleuze (1973) em uma conferência sobre Nietzsche se pergunta: quem é hoje o jovem nietzschiano? E uma das respostas é: "Pelo que conheço, um dos textos recentes mais belos, mais profundamente nietzschianos, é o texto em que Richard Deshayes escreve: Viver, não é sobreviver, exatamente antes de receber uma granada durante uma manifestação" (DELEUZE, 2006, p. 319).

ii "A civilização se define pela descodificação e pela desterritorialização dos fluxos na produção capitalista" (DELEUZE; GUATTARI, 2010, p. 325).

iii Quanto ao uso da noção de esquizofrenia deve-se ter cuidado: ela pode ser compreendida como "doença mental", categoria psiquiátrica. Mas, sobretudo, e eis o modo como mais a utilizamos aqui: trata-se de pensa-la como a realidade mesma do desejo, e assim ela funciona como conceito. E mais: esquizofrenia compreendida deste modo também tem como correlatos: viagem/processo esquizofrênico; fluxos esquizos (Cf. DELEUZE; GUATTARI, 2005; 2006; 2010). Portanto, vale acrescentar, jamais se tratou do elogiou da loucura ou do louco, mas acima de tudo de uma teoria do desejo que é pensada a partir da esquizofrenia. Tudo isto é mais bem elucidado no capítulo I d'O Anti-Édipo.
} 
iv Em O Anti-Édipo - mais especificamente no capítulo III do livro - Deleuze e Guattari apresentam a hipótese de três socius: socius primitivo; socius bárbaro; socius capitalista. Com base nisto estes dois filósofos franceses pensam uma teoria do desejo - desejo que é produção - e mostram como em cada socius o desejo flui, mas também é reprimido.

v Ficha Técnica: Título Original: Fight Club; Ano do lançamento: Outubro/1999; Duração: 139min; Produção: Art Linson, Cean Chaffin, Ross Grayson Bell; Gênero: Thriller; Direção: David Fincher; Roteiro: Chuck Palahniuk e Jim Uhls. Filme adaptado do livro do escritor e jornalista estadunidense Chuck Palahniuk Clube da luta (1996).

vi Endereço [http://www.pucsp.br/nucleodesubjetividade/ueinzz.htm]. [12/08/2016]. 